\title{
Digital rock models of Precambrian and Paleozoic tight formations from Poland
}

\author{
Paulina Izabela KRAKOWSKA ${ }^{1, *}$
}

1 AGH University of Science and Technology, Faculty of Geology, Geophysics and Environmental Protection, Department of Geophysics, al. A. Mickiewicza 30, 30-059 Kraków, Poland

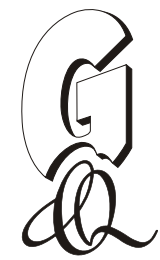

Krakowska, P.I., 2017. Digital rock models of Precambrian and Paleozoic tight formations from Poland. Geological Quarterly, 61 (4): 896-907, doi: 10.7306/gq.1386

Properties of selected Precambrian and Paleozoic sedimentary clastic rocks were analysed with respect to their reservoir potential. Multidimensional analysis of laboratory results and borehole logging data was used to construct digital models of pre-Mesozoic, deeply buried formations, present as tight, low-porosity and low-permeability rocks. This modern statistical and deterministic approach as applied to laboratory and borehole logging results worked to integrate data at different scales. The results obtained are useful not only in further scientific research but also found a use in industrial application. As a first step, statistical methods, including clustering and separation of homogeneous groups, enabled digital rock model creation on the basis of the results of such laboratory measurements as pycnometry, mercury porosimetry, nuclear magnetic resonance spectroscopy or computed X-ray tomography. Next, the models constructed were applied in borehole logging interpretation to find intervals with similar petrophysical properties within the group and different properties between the groups. This approach allowed implementation of upscaling procedures of laboratory experiments at micro- and nano-scale to borehole logging scale. High correlations were established between the log petrophysical parameters within the digital models. This approach can be used to divide the succession cored into intervals with different petrophysical parameters.

Key words: digital rock models, Precambrian and Paleozoic sedimentary rocks, petrophysical parameters, statistical analysis of petrophysical data.

\section{INTRODUCTION}

Precambrian and Paleozoic sedimentary rocks may reveal reservoir potential, i.e. the ability to accumulate hydrocarbons or water in economically viability amounts (Kotarba, 2010; Semyrka et al., 2010). Currently in Poland, the low-porosity and low-permeability Rotliegend formation is the subject of intense research as a tight gas reservoir (Kiersnowski et al., 2010; Such et al., 2010; Jarzyna et al., 2013). Silurian and Ordovician shale gas formations are the subject of the most intense studies as regards analysis of oil or gas contained in micropores (Poprawa and Kiersnowski, 2008; Poprawa, 2010; Porębski et al., 2013). Moreover, Cambrian and Carboniferous tight sandstones are under careful consideration in research on prospectivity and exploration (Botor et al., 2013; Wójcicki et. al., 2014).

Precambrian and Paleozoic sedimentary rocks are already studied as sedimentary basins and as regards recognition of lithospheric structure (Bakun-Czubarow, 1984), and may reveal reservoir potential, which in many aspects and applications, is the key-parameter and desired characteristics of rock formations. Investigations of tight gas reservoirs, shale gas formations and other low-porosity and low-permeability rocks present a great challenge for petrophysicists because the standard labora-

\section{*E-mail: krakow@agh.edu.p}

Received: April 27, 2016; accepted: August 7, 2017; first published online: September 25, 2017 tory and statistical methods applied to recognize geological properties are often inadequate. The method described in this paper can enrich the geological interpretation of tight rocks in using an unconventional approach in petrophysical analysis. The development of a comprehensive geological and non-standard petrophysical interpretation may help evaluate reservoir intervals in tight formations. There is a need to build a coherent methodology for the study of various rock properties and connecting the different features into characteristics, allowing rock clustering (Szabó, 2011; Puskarczyk et al., 2015; Jarzyna et al., 2015).

In this paper standard laboratory results (helium pycnometry, electric, ultrasonic and natural radioactivity tests, XRD analysis, mercury porosimetry, uniaxial compression strength tests, permeability measurements) were linked with the outcomes of the newest laboratory techniques (nuclear magnetic resonance spectroscopy, computed X-ray tomography). The main goal of the research was to construct a multidimensional data set, to construct adequate digital models of the rocks based on laboratory measurement results, and to combine this approach with borehole log information. Digital models of low-porosity and low-permeability tight rocks were constructed based on the results of laboratory measurements of mineralogical and petrophysical parameters using statistical methods of classification. These models are the representation of 3 groups of rocks with poor, medium and good reservoir potential. Next, the models, determined on the basis of laboratory data, were applied to borehole logging data regarding the same ranges of variation of selected parameters. This approach enabled focus on detailed analysis of the best and the worst reservoir parameters in representative sections of the geological profiles. 


\section{MATERIALS}

Geological samples were taken from 28 borehole cores (Fig. 1), with particular regard for low values of porosity and permeability in the samples. Then, the rock samples were selected, complying with four conditions:

- depth of the rocks $>3000 \mathrm{~m}$, and thus at similar temperature and pressure conditions in which material was occurred regarding present depth of deposition;

- rock age - Precambrian or Paleozoic. The study was concentrated on analysis of potentially gas or oil-bearing formations that are older than Mesozoic. Especially in age, when shale gas appeared to be potentially reservoir rock and exploration may be ended in future with success;

- lithology - siliciclastic (sandstones and mudstones);

- accessibility of geological material from cores. Several measurements were planned that demand a defined amount of material. Boreholes were selected for analysis from the Polish Geological Institute - National Research Institute, Central Geological Database (CBDG) Furthermore, available rock material from boreholes was checked regarding the possibility to probe core samples of $10 \mathrm{~cm}$ length and $1 / 4$ core diameter.

Rock samples consisted of 22 sandstones and 6 mudstones being potentially reservoir low porosity and low permeability rocks (Appendices 1 and $2^{*}$ ).

The samples analysed were very diverse lithologically, and hence in properties. This diversity of material meets the criteria of parameter randomness as needed in statistical justification. Therefore, samples could be analysed in order to find similarities in petrophysical features, even though they differed in age. Petrophysical analysis divides the rocks into the groups of similar properties. Paradoxically, geologically different material can reveal similar petrophysical properties and owing to this can be treated similarly in terms of exploration and production.

The research material was also characterized in terms of lithostratigraphic unit affinity (Marcinowski, 2004a, b). Sample 868 (Appendix 1) represents the Polesie Formation (Proterozoic) as the oldest sedimentary rock succession in the Polesie and Wołyń region with a thickness of up to $300 \mathrm{~m}$. The Cambrian sample 878 is from the Smołdzino Formation (Lower Cambrian) with a thickness of up to $87 \mathrm{~m}$ in the Baltic Syneclise, The Łeba area provided sample 874 of the Kostrzyń Formation (Middle Cambrian) comprising mainly quartz sandstones in the Lublin area. The Silurian sample 879 belongs to the Pelplin Claystones Formation (Llandoverian) rich in graptolites and occurring in the Baltic Syneclise (Modliński et al., 2006). Devonian formations are represented by samples 886 and 130: the Zwolen Formation (Lower Devonian, Emsian) deposited in the Radom and Lublin area and reaching a thickness of up to 1300 m; sample 881 of the Czarnolas Formation (Lower Devonian, Lochkovian) which occurs in the Radom area and consists of mudstones and laminated claystones with quartz sandstones; and sample 139, of the Telatyń Formation (Middle Devonian, Eifelian) from the Lublin area with a thickness of up to $250 \mathrm{~m}$. Sample 137 is from the Gozd Formation (Lower Carboniferous, Tournaisian) of the Laska-Czaplinek zone and composed of dark grey claystones; sample 887 is of the Drzewiany Sandstones Formation occurring in the Koszalin-Wierzchowo zone with a thickness of up to $300 \mathrm{~m}$; sample 890 is of the Łobżonka Claystones Formation (Lower Carboniferous,
Visean) consisting of black claystones, dark grey mudstones and quartz sandstones; and samples 129 and 141 are of the Lublin Coal Formation (Upper Carboniferous, Westphalian) in the area of Lublin and composed of sandstones and mudstones. To the clastic Rotliegend Formation, occurring in the Permian Basin of Poland and Germany, belong several samples: 891, 892 and 893 (Permian). Samples 869, 870, 871, $872,873,876,877,883,888,889,894$ and 896 were not assigned to lithostratigraphic formations based on geological descriptions (according to the CBDG) but met the criteria for low-porosity and permeability.

The samples thus differ in age, lithology (sandstones or mudstones) and depositional area but all of them fulfilled the requirements of low porosity and permeability values, as confirmed by the laboratory measurements. Petrophysical studies revealed similarity in sample features, important for determination of reservoir potential, despite not taking into consideration the detailed geological characteristics of the samples (detail macroscopic description, facies etc.)

\section{METHODS}

Laboratory measurements were carried out on the core samples to provide comprehensive analysis of the physical parameters, with particular emphasis on the reservoir and elastic properties of the Precambrian and Paleozoic sedimentary rocks. Reservoir parameters: porosity and permeability were essential objects of the laboratory analysis determining the reservoir potential. Total porosity $(K p)$ was estimated using helium pycnometry, while effective porosity was estimated using mercury injection porosimetry ( $K p \mathrm{mp}$ ef), nuclear magnetic resonance experiments (the sum of clay-bound water $K p 1$, capillary-bound water $K p 2$ and free water $K p 3$ ) and X-ray computed microtomography $(K p \mu-C T)$. The assessment of physical permeability $(k)$ was carried out using a permeameter.

Several laboratory measurements were applied to study the core samples. Laboratory measurements were selected based on the information they provide (each method is based on different physical law) and applications of modern methods (nuclear magnetic resonance spectroscopy and computed X-ray tomography) to low porosity and low permeability rocks in order to retrieve the most detailed rock descriptions. Bulk density $(\delta b)$ and total porosity $(K p)$ were determined using two devices: a gas pycnometer AccuPyc 1330 and a density analyzer GeoPyc 1360. Permeability $(k)$ was estimated on the basis of a Gas Permeameter Temco taking into consideration the Klinkenberg effect (Klinkenberg, 1941). An Escort ELC 3131D device provided values of the cementation factor $(m)$, while an ultrasonic flow detector UMT-17 Ultramet Co. provided P- and S- wave velocity values ( $\mathrm{Vp} / \mathrm{Ns}$ ratio). Natural radioactivity, potassium $(K)$, uranium $(U)$ and thorium $(T h)$ content, were detected using a three-channel gamma spectrometer MAZAR. Determination of shaliness $(\mathrm{Vcl})$ was conducted by an X-ray diffractometer $X$ 'Pert MPD Philips Co. Nuclear magnetic resonance analysis (NMR Maran-7, field intensity $0.186 \mathrm{~T}$ ) provided clay-bound water $(K p 1)$, capillary-bound water $(K p 2)$ and moveable water (Kp3) (Coates et al., 1999). On the basis of NMR results logarithmic $T_{2}$ mean $\left(T_{2} M L\right)$ was calculated (Straley et al., 1997). Noninvasive computed X-ray microtomography (Benchtop CT160 tomograph) gave information about the total porosity $(K p \mu-C T)$ and homogeneity parameter $(J)$ by detailed $2 \mathrm{D}$ and 3D image analysis (Stock, 2009; Bielecki et al., 2009; Dohnalik,

\footnotetext{
* Supplementary data associated with this article can be found, in the online version, at doi: 10.7306/gq.1386
} 


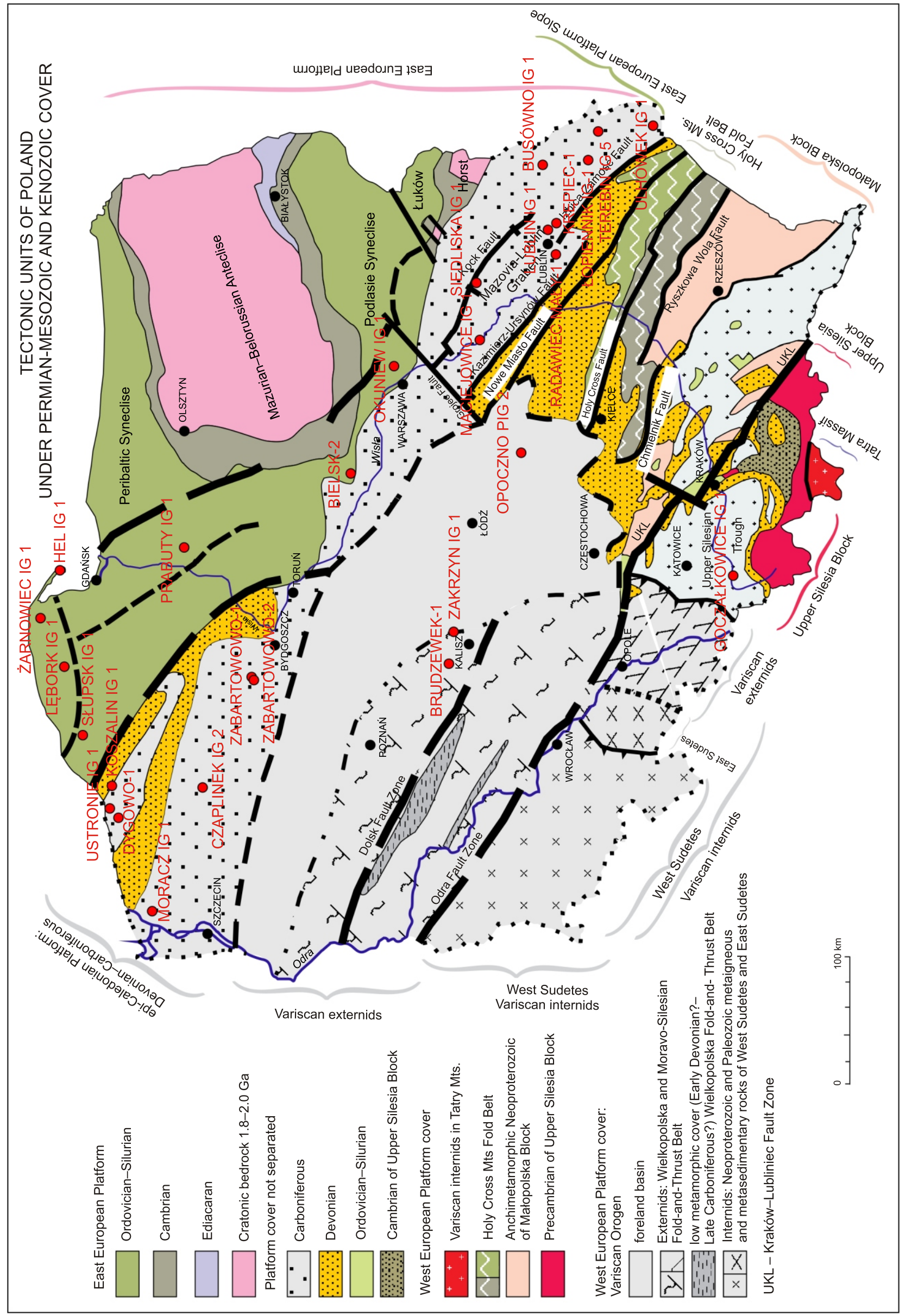

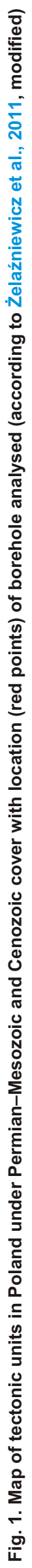


2013). In the case of the homogeneity parameter a reference value for the relative standard deviation of 0.16 was adopted, which has been designated for the white Szydłowiec sandstone (recognized in the Oil and Gas Institute in Krakow, Poland as a standard for uniform pore space). Moreover, CT measurements provided information about the quality of pore space development (pore channel connectivity). Poor development of pore space in samples 887, 888, 891, 129 and 141 allowed inclusion of these samples to the analysis, despite the porosity values exceeding 10\%. Mercury injection porosimetry (Pittman, 1992), using an AutoPore /I 9220 Micrometrics Co., gave information on effective porosity ( $K p \mathrm{mp}$ ef) and average pore diameter ( $D$ av). The Swanson parameter (S1) for the first porous system was determined on the basis of mercury injection pressure versus mercury volume and was related to rock filtration ability (Swanson, 1981). Compressional strength $(R c)$ was estimated using a Verkstoffprufmachinen Leipzig testing machine $400 \mathrm{kN}$ with maximum force and applying a uniaxial compression test (Brace, 1966). Mineralogical (XRD analysis in the Oil and Gas Institute - National Research Institute, Kraków) and petrophysical characteristics of the research material are given in Appendices 1 and 2.

The combination of different methods used in estimating porosity provided parameters connected with different pore sizes and types because of differences in the physical phenomena used in the measurements and the specific resolution of the devices. Hence, resolution of microtomography results are within the range of gas bubbles and oil drops (micrometres), so the extracted porosity informs about the pore space consisting of pores with specific diameters, both connected and closed. Connected pores can be extracted from the CT images and be efficiently used in effective fluid flow modeling. On the other hand, mercury porosimetry provides porosity regarding pores with diameters above $3 \mathrm{~nm}$ but only if they are connected.

Statistical methods, i.e. clustering and separation of homogeneous groups, enabled creation of digital rock models on the basis of the results of laboratory measurements and consisted of different petrophysical parameters (Krakowska et al., 2016). In order to extend the point information from laboratory measurements, correlations between laboratory results and borehole log data were made. Borehole log data, mostly archival was processed and interpreted with the use of specialist software (Techlog, Schlumberger) and provided rock parameters in their natural habitat conditions (pressure and temperature). Next, established digital models were used in the secondary processing and interpretation of borehole logging results. Corresponding petrophysical parameters from laboratory measurements and from borehole logs were compared, e.g. sum of clay minerals (lab) and shaliness (log); total porosity from lab and log; thorium, uranium and potassium concentration from lab and spectral gamma ray log. Hence, specific intervals in boreholes were selected on the basis of characteristic parameters values for digital models 1,2 and 3. This approach allowed for the implementation of upscaling procedures on results from measurements conducted in the laboratory, at the micro (and nano) scale and borehole logging in the meso scale (Dvorkin et. al., 2008). New technology applied to the different scale results enabled integration and detailed characterization of reservoir pore space and allowed extension of the concept of reservoir rocks beyond the criteria used to date (Krakowska and Puskarczyk, 2015). The results obtained are useful in further conceptual studies.

Digital rock model construction was initiated by clustering the data into homogeneous groups, with similar petrophysical parameters within each group (Tryon, 1939). Cluster Analysis with Generalized k-Mean Method in Statistica software was ap- plied to selected parameters to enable data division into groups (clusters) distinctly different from each other. Groups of similar values of parameters were detected, each with different values in relation to the rest of the groups detected (StatSoft, 2011). V-Fold Cross-Validation was applied to the Classical k-Means Algorithm, which allowed identification of the optimal number of models within the given lithology (Hartigan and Wong, 1978). The user has to approve the number of clusters by analyzing the results and can modify these numbers if the results are not sufficient, i.e. if there are too many clusters or too many detached parameter values in clusters. A classical algorithm was selected because it allowed cluster construction in the absence of several parameters for any given samples. Finally, three groups of parameters (clusters) were chosen and applied to petrophysical interpretation as the 1st, 2nd and 3rd digital rock models reflecting medium, poor and good reservoir potential respectively.

Parallel efforts were made to reduce the number of parameters in the clusters and to obtain the optimal number of clusters (models). It was necessary to select the parameters on which the influence on description of tight rock potential is the strongest. Moreover, the analysis was performed several times for different sets of parameters, assessing the value of the error function and studying the correlation graphs for selected parameters within the groups. Finally, a group of parameters was established for cluster analysis that consisted of: bulk density, total porosity (pycnometer), absolute permeability, $P$ - and $S$-wave velocity ratio, cementation factor, content of potassium, thorium and uranium, shaliness, effective porosity, average pore diameter, Swanson parameter for the first porous system responding to the highest injection pressure and highest pore diameter from mercury porosimetry, clay-bound water, capillary-bound water and moveable water content, logarithmic $T_{2}$ mean from the whole NMR signal, total porosity, homogeneity parameter from computed microtomography and compressive strength from uniaxial compressional tests (Fig. 2 and Appendix 2).

Standard petrophysical interpretation of borehole logs (e.g., gamma ray, sonic and resistivity log) was carried out in order to obtain shaliness, porosity and water/hydrocarbon saturation from the boreholes analysed. Firstly, petrophysical profiles of the boreholes, consisting of several log characters such as shaliness, porosity, transit travel time (DT), were divided into intervals on the basis of parameter comparison between digital rock models (minimum, maximum, average values of parameters in each model) and logs. In the intervals, which cover the depth of the models selected, mutual relationships between log parameters were established. Hence, the parameters from the logs include the ranges of lab parameters in models within borehole intervals. All the relations derived helped in detailed analysis of the rocks as regards hydrocarbon saturated zone determination and lithology recognition (Dudek and Stadtmuller, 2010). This approach in constructing the digital rock models from lab measurements and their application to borehole logs enabled restricting focus of the detailed analysis only to representative sections of the geological profiles. This can also support the decision of core typing and limit the amount of coring intervals only to those with interesting, different physical parameters, e.g. interesting reservoir parameters. Regarding the specific reservoir, this approach can be carried out on one prospective well and transfered to other wells. The whole interval represented in the form of borehole logs (measured and as result of interpretation) can be divided into sections which correspond to the digital rock models. The digital rock models were obtained from laboratory measurements so the accuracy of petrophysical parameter determination is higher than from borehole logs, e.g. total porosity from helium 


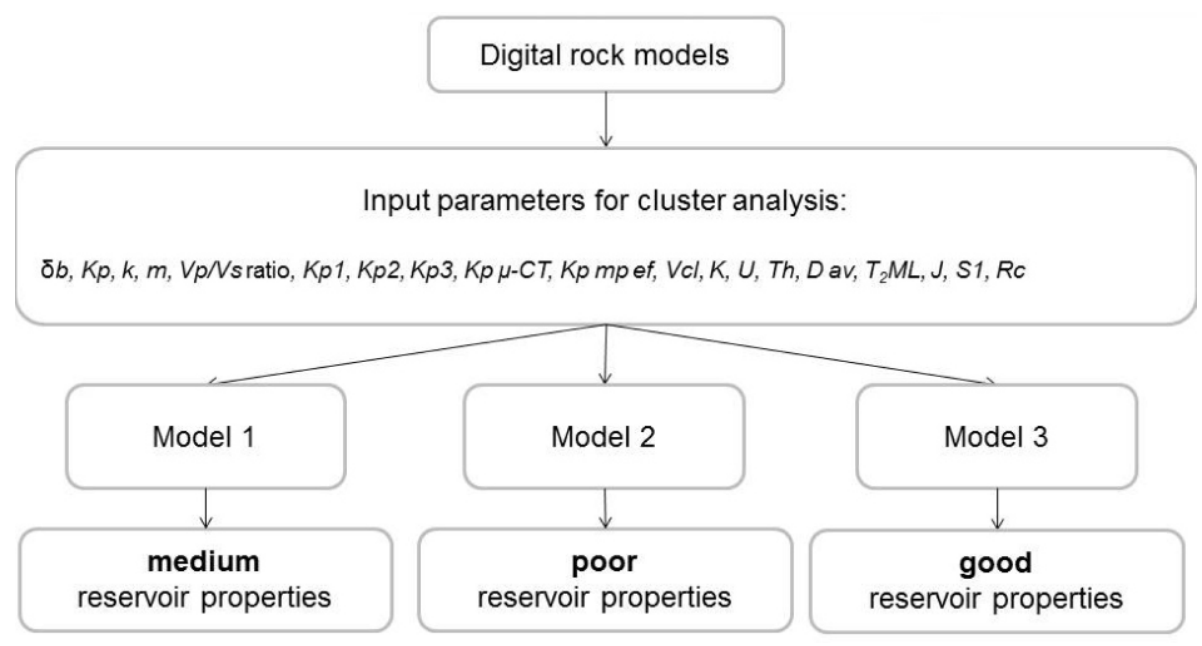

Fig. 2. Scheme of digital rock model construction

Symbols are explained in Table 2

pycnometer and sonic log. So, the intervals with the best and the worst reservoir parameters can be easily determined. Summarizing, the nano and micro scale results of laboratory measurements in digital rock models were transferred into the meso scale results obtained from borehole logging.

Borehole logging analysis was conducted to include the results of laboratory measurements. Depth fitting of both types of data was carried out before the analysis. A slight depth shift was necessary because of the different vertical resolution of point data from laboratory measurements in comparison to borehole logging results and this was achieved by comparison of gamma ray log, compressional slowness, cores descriptions and laboratory measurement results with depth. There was also considered the influence of poor depth estimation of very old core samples, that were not well preserved.

\section{RESULTS}

The most important petrophysical parameters, derived from laboratory measurements contributing key information about the reservoir potential of tight reservoirs, were selected to construct the digital models (Fig. 2). Consequently, the results shown (Table 1) encompassed the clusters that were separated on the basis of the parameters of the highest variability. The clusters created corresponded with the three digital rock models of tight formations, characterized by distinct values of physical parameters. Figure 2 presented the scheme of digital rock model classification based on cluster analysis with division into 3 models and Appendix 3 contained basic statistics for the models distinguished.

The clastic tight formations were divided into three groups through obtaining the lowest error function of cluster analysis. The groups represent three different digital models. The qualitative characteristics of the models are shown in Table 2.

Model 2 was characterized by the highest values of bulk density compared to the rest of the groups, with the lowest values of total porosity from pycnometer results together with the lowest $\mu-C T$ porosity and effective porosity from mercury porosimetry (Fig. 3). Figure 3 shows 3 models. Model 2 is revealed through high bulk density and low total porosity values. However, the points clustered into two areas connected with different lithology, not with difference in petrophysical parame- ters. The lowest values of bulk density and highest porosity singled out model 3. Parameters characteristic for model 1 show values in between those of models 2 and 3 .

Full quantitative analysis of all models is given in Appendix 3 and Table 2. Maximum absolute permeability values were in model 3 and the lowest in model 2. Impermeable rocks were assigned to model 1. Clay-bound water showed the highest values in models 1 and 3 and the lowest in model 2 whereas the moveable water was highest in model 3 with models 1 and 2 having comparable amounts. The parameter reflecting the percentage of clay-bound water, capillary-bound and moveable water was the logarithmic $T_{2}$ mean, which had the highest values in model 3 and lowest in model 1 . The highest value of total porosity from $\mu-C T$ and effective porosity from mercury porosimetry was characteristic for model 3 and the lowest for model 2. Model 3 was defined by the lowest shaliness compared to models 1 and 2, associated with the lowest content of radioactive elements. The highest values of average pore diameter were obtained in model 3 and the lowest in model 2 . This rule was also reflected in values of the Swanson parameter: the lowest for model 3 and high in the models 1 and 2 . The homogeneity parameter from $\mu-C T$ had the highest values in model 1 , and the lowest in model 3 . This result showed the influence of grain size, roundness and sorting on the reservoir properties, especially on permeability. Uniaxial compressive strength proved that the most resistant rocks belonged to model 2 and the least resistant to model 3 . This result correlated well with porosity (higher porosity, lower strength to uniaxial compression).

The best reservoir properties were assigned to model 3 and the worst properties to model 2. The best reservoir properties were described for instance by high total and effective porosity and permeability, low bulk density, low shaliness, high average pore diameter and the worse properties for instance by low porosity and permeability, high shaliness, high Swanson parameter. Model 3 was created from sandstones, mainly Carboniferous and Cambrian (2 samples - Cm, 1 sample - O, 1 sample $D, 4$ samples - C, 1 sample - P), however, in model 2 there were sandstone and mudstone samples of different ages (2 samples - Cm, 1 sample - S, 2 samples - D, 1 sample - C, 2 samples $-\mathrm{P}$ ). Model 1 was represented mainly by Carboniferous and Cambrian sandstones ( 1 sample-Pt, 3 samples $-\mathrm{Cm}$, 1 sample - S, 2 samples - D, 4 samples - C). On the basis of digital models in the Carboniferous and Cambrian sandstones 
Results of cluster analysis - selection of samples

\begin{tabular}{|c|c|c|c|c|c|c|}
\hline Model & Sample no. & Borehole & Age & Lithology & Depth & Geologic unit \\
\hline \multirow{11}{*}{1} & 889 & Brudzewek-1 & C & $\mathrm{C}$ & 3818 & Fore-Sudetic Homocline \\
\hline & 894 & Zabartowo-2 & $\mathrm{C}$ & $\mathrm{s}$ & 4500 & Pomeranian Anticlinorium \\
\hline & 890 & Moracz IG 1 & Cwi & $\mathrm{s}$ & 4650 & Pomeranian Anticlinorium \\
\hline & 896 & Opoczno PIG 2 & Cwi & $\mathrm{s}$ & 3045 & Holy Cross Mts. Anticlinorium \\
\hline & 881 & Maciejowice IG 1 & D1 & $\mathrm{s}$ & 4374 & Warsaw Synclinorium \\
\hline & 130 & Krępiec-1 & Dem & $\mathrm{C}$ & 4501 & Lublin Synclinorium \\
\hline & 872 & Słupsk IG 1 & Sw & $\mathrm{C}$ & 3546 & Peri-Baltic Syneclise \\
\hline & 874 & Łopiennik IG 1 & $\mathrm{Cm} 2$ & $\mathrm{~s}$ & 4588 & Lublin Synclinorium \\
\hline & 869 & Hel IG 1 & $\mathrm{Cm} 1$ & $\mathrm{~s}$ & 3457 & Peri-Baltic Syneclise \\
\hline & 876 & Siedliska IG 1 & $\mathrm{Cm} 1$ & $\mathrm{~s}$ & 3007 & Mazovia-Lublin Graben \\
\hline & 868 & Busówno IG 1 & $\mathrm{Pt}$ & $\mathrm{s}$ & 4153 & Lublin Synclinorium \\
\hline \multirow{8}{*}{2} & 892 & Czaplinek IG 2 & $\mathrm{P} 1$ & $\mathrm{~s}$ & 4016 & Pomeranian Anticlinorium \\
\hline & 893 & Zabartowo-1 & P1 & $\mathrm{C}$ & 3956 & Pomeranian Anticlinorium \\
\hline & 137 & Dygowo-1 & $\mathrm{Ct}$ & $\mathrm{s}$ & 3790 & Pomeranian Anticlinorium \\
\hline & 139 & Radawiec Mały-1 & $\mathrm{De}$ & $\mathrm{C}$ & 4304 & Lublin Synclinorium \\
\hline & 886 & Ulhówek IG 1 & Dem & $\mathrm{s}$ & 3037 & Lublin Synclinorium \\
\hline & 879 & Lębork IG 1 & Sla & C & 3247 & Peri-Baltic Syneclise \\
\hline & 873 & Goczałkowice IG 1 & $\mathrm{Cm}$ & $\mathrm{s}$ & 3012 & Upper Silesian Trough \\
\hline & 871 & Prabuty IG 1 & $\mathrm{Cm} 2$ & $\mathrm{~s}$ & 3460 & Peri-Baltic Syneclise \\
\hline \multirow{9}{*}{3} & 891 & Zakrzyn IG 1 & $\mathrm{P} 1$ & $\mathrm{~s}$ & 4425 & Fore-Sudetic Homocline \\
\hline & 129 & Bielsk-2 & $\mathrm{Cw}$ & $\mathrm{s}$ & 4545 & Warsaw Synclinorium \\
\hline & 141 & Bielsk-2 & Cw & $\mathrm{s}$ & 4589 & Warsaw Synclinorium \\
\hline & 887 & Koszalin IG 1 & Cwi & $\mathrm{s}$ & 3008 & Pomeranian Synclinorium \\
\hline & 888 & Ustronie IG 1 & $\mathrm{Ct}$ & $\mathrm{s}$ & 3154 & Pomeranian Anticlinorium \\
\hline & 883 & Lublin IG 1 & D2 & $\mathrm{s}$ & 4508 & Lublin Synclinorium \\
\hline & 877 & Terebin IG 5 & Ot & $\mathrm{s}$ & 3034 & Lublin Synclinorium \\
\hline & 878 & Żarnowiec IG 1 & $\mathrm{Cm} 1$ & $\mathrm{~s}$ & 3233 & Peri-Baltic Syneclise \\
\hline & 870 & Okuniew IG 1 & $\mathrm{Cm} 1$ & $\mathrm{~s}$ & 4106 & Warsaw Synclinorium \\
\hline
\end{tabular}

s - sandstone, c - claystone, Pt - Precambrian, Cm1 - Lower Cambrian, Cm2 - Middle Cambrian, Cm - Cambrian, Ot - Ordovician, Tremadoc, Sla - Silurian, Llandoverian, Sw - Silurian, Wenlock, D1 - Lower Devonian, D2 - Middle Devonian, Dem - Devonian, Emsian, De - Devonian, Eifelian, Cwi - Carboniferous, Visean, Ct - Carboniferous, Tournaisian, Cw Carboniferous, Westphalian, C - Carbonifereous, P1 - Lower Permian

Table 2

Classification of the digital model parameters, and qualitative description of parameter values in the model specified

\begin{tabular}{|c|c|c|c|}
\hline Parameter & Model 1 & Model 2 & Model 3 \\
\hline Bulk density $(\delta b)$ & medium & highest & lowest \\
\hline Total porosity $(K p)$ & medium & lowest & highest \\
\hline Absolute permeability $(k)$ & impermeable & lowest & highest \\
\hline Cementation factor $(m)$ & comparable & comparable & highest \\
\hline$P$ - and S-wave velocity ratio (Vp/Vs ratio) & highest & lowest & medium \\
\hline Clay-bound water (Kp1) & medium & lowest & highest \\
\hline Capillary-bound water (Kp2) & medium & lowest & highest \\
\hline Moveable water (Kp3) & comparable & comparable & highest \\
\hline Logarithmic $T_{2}$ mean $\left(T_{2} M L\right)$ & lowest & medium & highest \\
\hline Total porosity $(K p \mu-C T)$ & medium & lowest & highest \\
\hline Homogeneity parameter $(\mathrm{J})$ & highest & medium & lowest \\
\hline Effective porosity (Kp mp ef) & medium & lowest & highest \\
\hline Average pore diameter ( $D$ av) & medium & lowest & highest \\
\hline Swanson parameter (S1) & highest & medium & lowest \\
\hline Clay content $(V c)$ & medium & highest & lowest \\
\hline Potassium content $(K)$ & highest & medium & lowest \\
\hline Uranium content $(U)$ & highest & medium & lowest \\
\hline Thorium content (Th) & highest & medium & lowest \\
\hline Compressional strength (Rc) & medium & highest & lowest \\
\hline
\end{tabular}




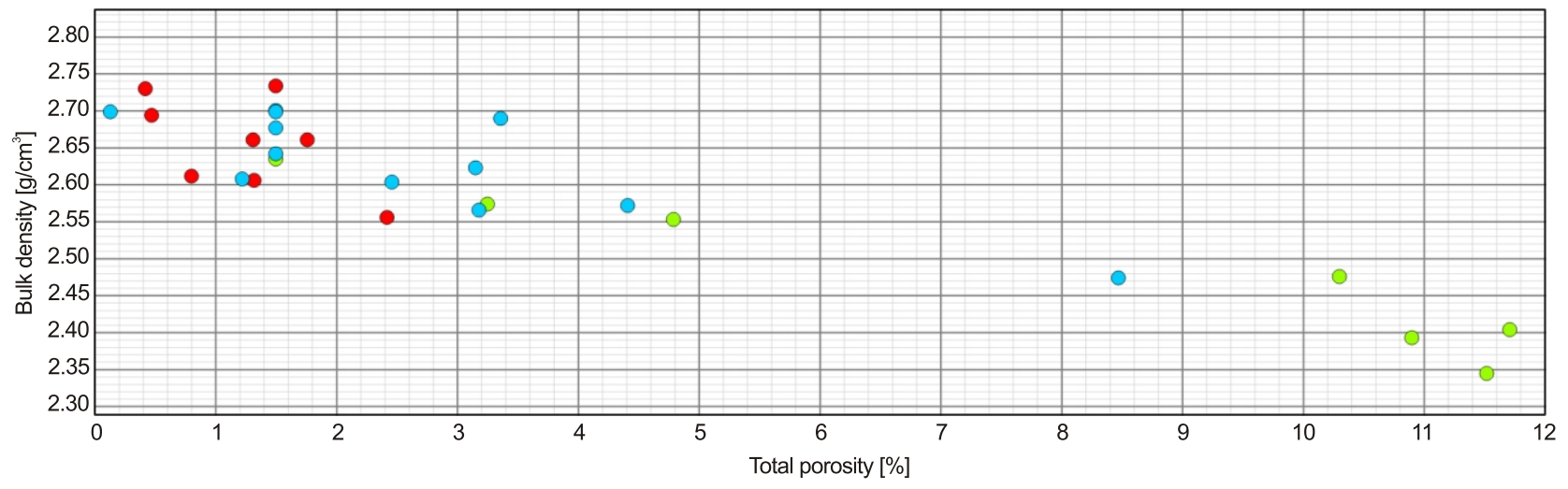

Fig. 3. Bulk density $(\delta b)$ vs. total porosity $(K p)$

Model 1 - blue, model 2 - red, model 3 - green

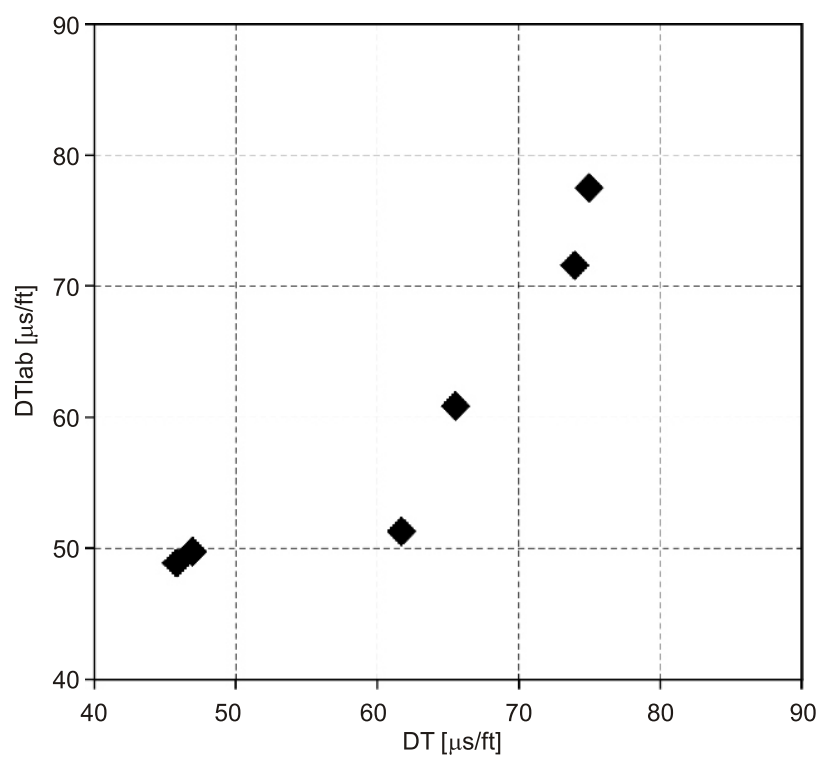

Fig. 4. Interval transit time from lab measurements (DTlab) vs. acoustic $\log (\mathrm{DT})$

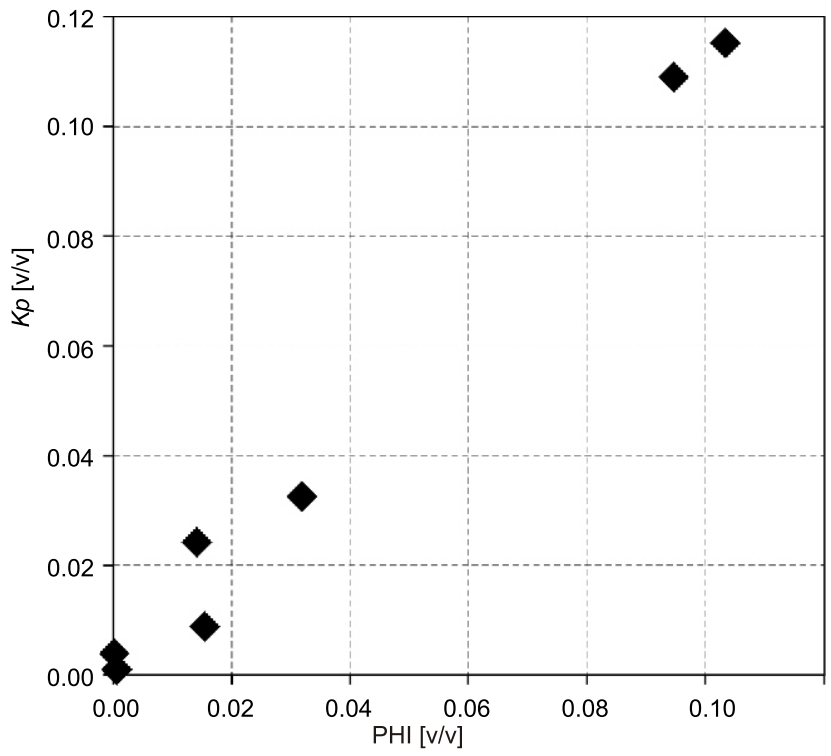

Fig. 5. Total porosity from lab measurements $(K p)$ vs. total porosity from borehole log interpretations (PHI)

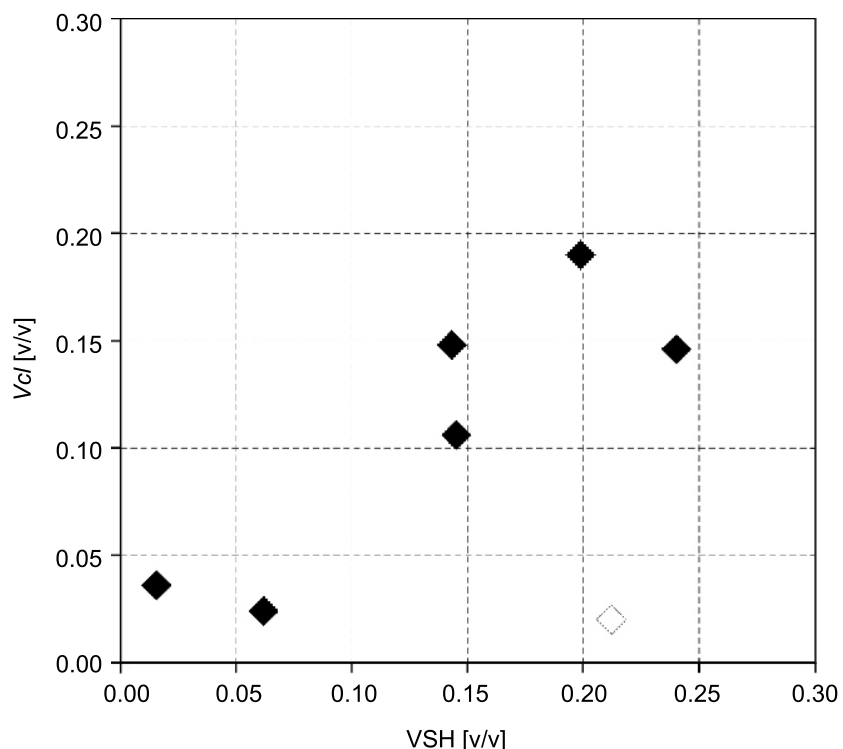

Fig. 6. Shaliness from lab measurements $(V c l)$ vs. borehole log interpretations (VSH)

two separate groups were selected, the first (model 3) of good reservoir properties, i.e. excellent reservoir potential and the second (model 1) of moderate reservoir properties (moderate reservoir potential).

Petrophysical parameters derived from both methods for all boreholes and models were compared and some discrepancies were observed (Figs. 4-6). There are only a few points out of 28 because suitable logs were not available for all boreholes. One point on each figure represents one core sample assigned to borehole log information.

Intervals with parameters (shaliness, porosity, transit travel time) corresponding to the digital models were analysed in detail in the boreholes Bielsk-2, Mełgiew-9, Maciejowice IG 1, Dygowo-1 and Terebin IG 5. These boreholes were selected as exemplary with full borehole log information from different logging methods such as resistivity logs. The ranges of parameters (for instance total porosity, shaliness) obtained from the characteristics of the digital models were assigned to borehole logs. Selection of parameters was connected with the accessibility of selected borehole logs and compatibility of borehole logging data with the laboratory results. Intervals that met the criteria connected with the parameters from logs included in models from laboratory measurements were searched and highlighted, 
allowing for proper assignment of rocks to the digital models distinguished. Correlations between parameters determined from borehole logs were calculated in those intervals. Correlation coefficients $>0.6$ at the selected model intervals supported the affiliation of rock intervals to the digital models.

The relation of the total porosity and spectral gamma ray data with subtracted counts from the uranium window in Bielsk-2 borehole showed satisfactory (model 1) and unsatisfactory (model 3) fits (Fig. 7) according to statistical interpretation of the determination coefficient ( $R^{2}$ adj).

The relationship between neutron porosity and apparent resistivity in the Mełgiew-9 borehole in the Devonian and Carboniferous formations distinguished allowed the selection of intervals in which the data matched model 3 (Fig. 8). Intervals were separated to distinguish zones with similar petrophysical properties. Moreover, satisfactory fitting was observed in the highlighted areas. Log samples from model 3 clustered in two groups with high resistivity, low neutron porosity (1 group) and low resistivity and high neutron porosity ( 2 group) which is connected with change in lithology: gas-bearing sandstones ( 1 group) and gas-bearing mudstones ( 2 group). However, this is difference only in rock lithology, with similarity in petrophysical parameters as reflected by affiliation to model 3 .

Satisfactory fit was also noted for petrophysical parameters of model 1 based on interval transit time and natural radioactivity for Precambrian rocks in the Terebin IG 5 borehole. The determination coefficient was equal to 0.68 (Fig. 9). Only 5 sam- ples were assigned to model 2 (red). Samples from model 3 (green) occurred in the zone of high interval transit times and low natural radioactivity.

Intervals of the geological profile corresponding to the preferred digital models were identified in the Maciejowice IG 1 borehole. The relationship between shaliness calculated on the basis of GR log (VSH) and interval transit time (DT) revealed almost linear dependence for models 1 and 2 marked in blue and red colors, respectively. Model 3 comprised formations with the lowest shaliness (Fig. 10).

The combination of natural radioactivity and the interval transit time (Fig. 11) in borehole Dygowo-1 allowed demonstration of the relationship between the highlighted models. A linear reverse relationship was observed for models 1 and 2, and a non-linear relationship for model 3 . It is shown in this example that only for natural radioactivity and interval transit time, points from model 1 comprise points from model 2. For different parameters these kinds of effect can appear and be apparent because model 1 contains information from rocks with moderate reservoir parameters, so it can include some parameters with the worst characteristics.

\section{DISCUSSION}

The results of laboratory measurements on the core samples provided physical properties of Precambrian and Paleo-

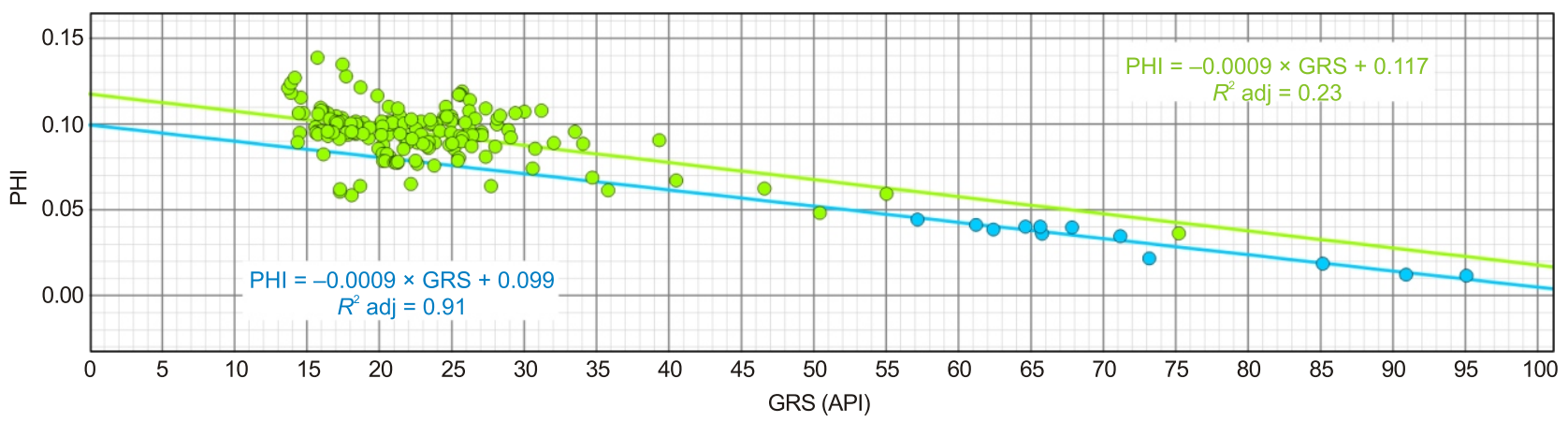

Fig. 7. Total porosity calculated from compressional slowness (PHI) vs. intensity of natural radioactivity (uranium subtracted spectral gamma ray; GRS) for distinguished rock models

Bielsk-2 borehole; colours as in Figure 3

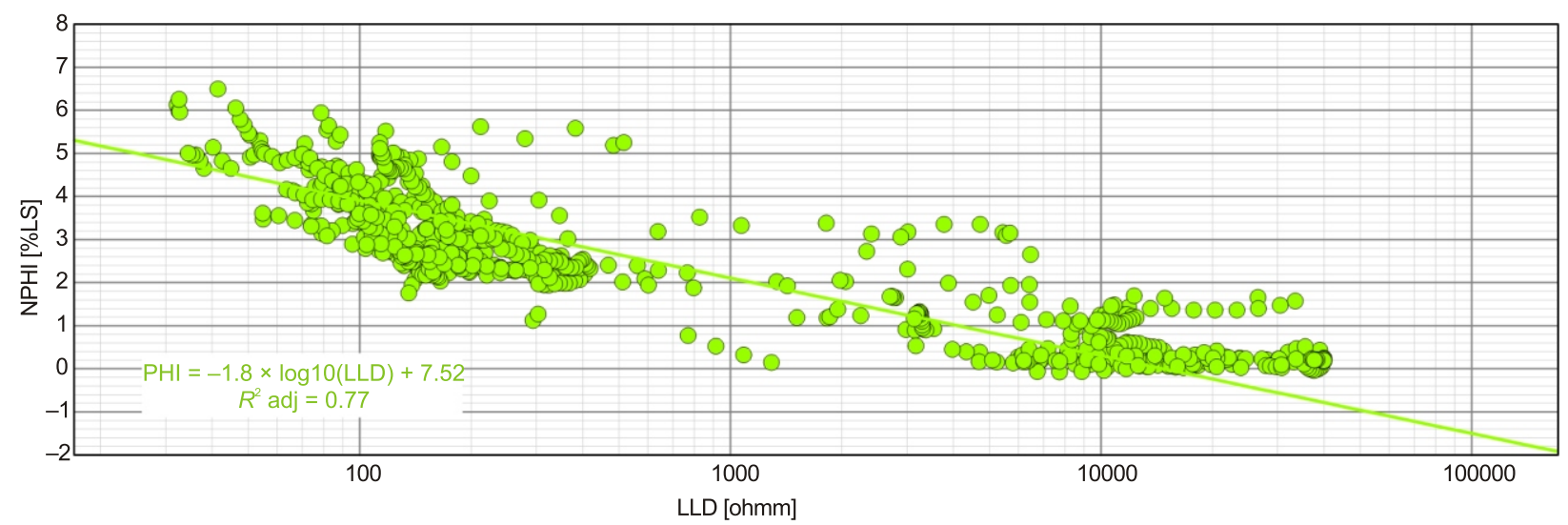

Fig. 8. Neutron porosity (NPHI) vs. apparent resistivity (LLD) for model 3 


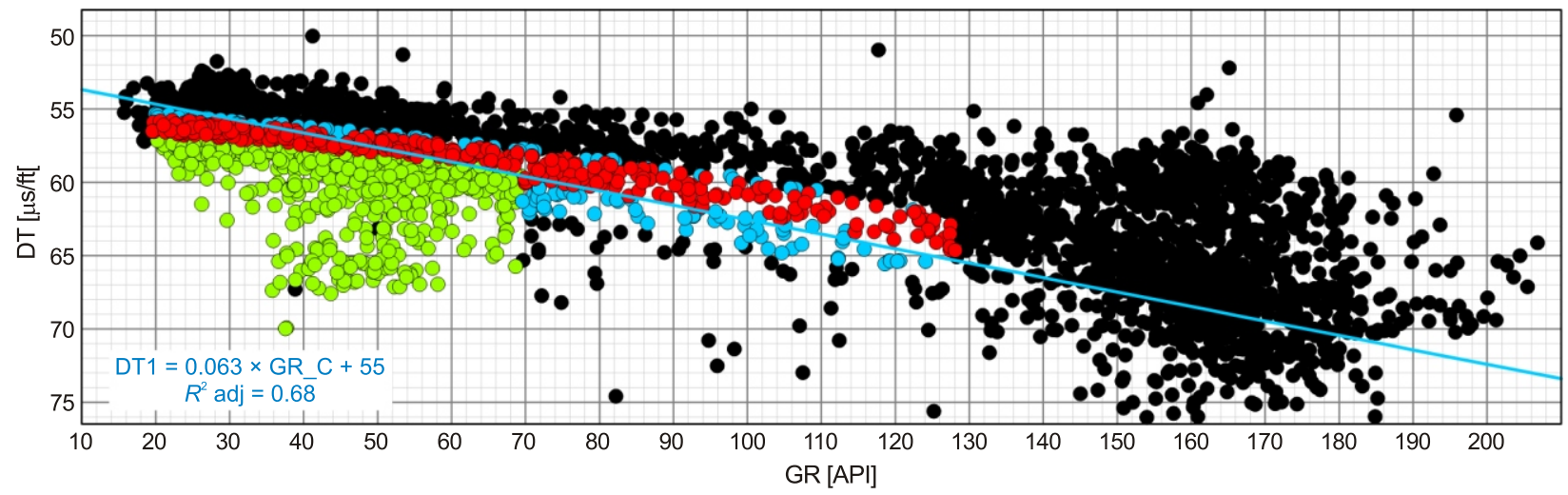

Fig. 9. Interval transit time (DT) vs. natural radioactivity (GR)

Precambrian samples; Terebin IG 5 borehole; colours as in Figure 3; black dots - Precambrian borehole log data without affiliation to the models

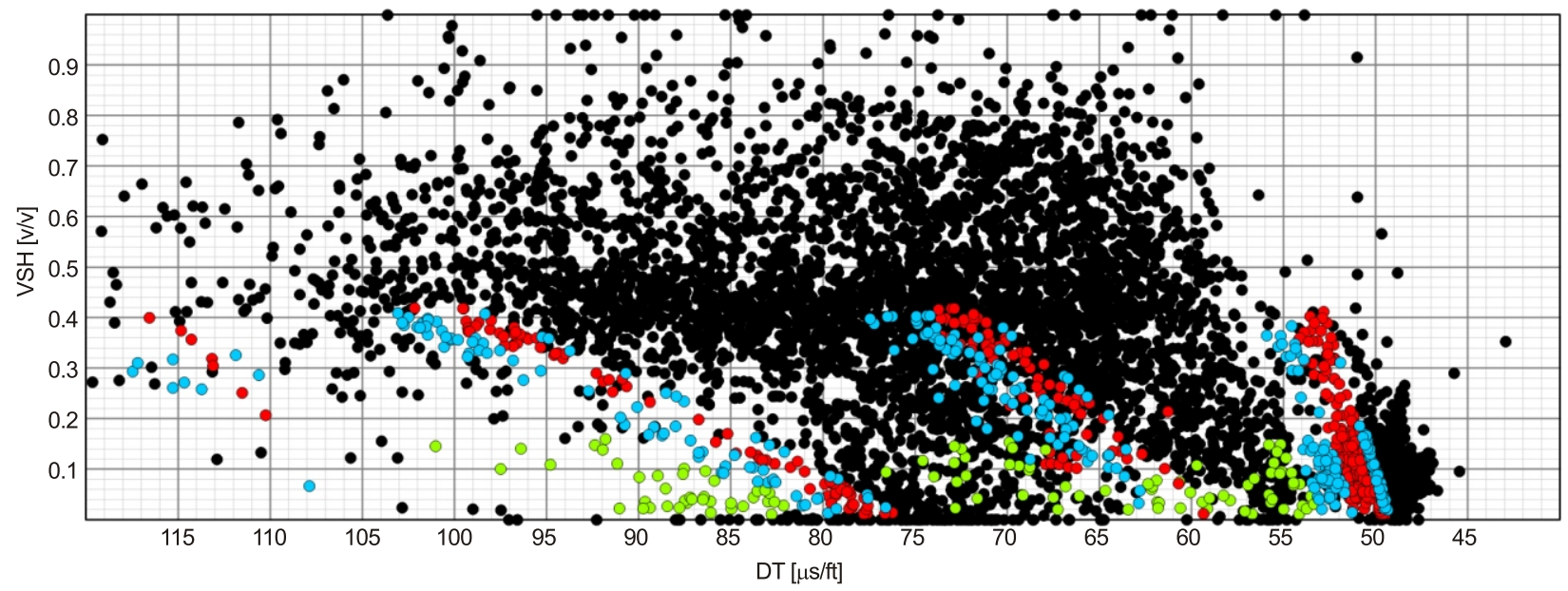

Fig. 10. Shaliness (VSH) vs. interval transit time (DT) for the rock models distinguished

Maciejowice IG 1 borehole; colours as in Figure 3; black dots - borehole log data without affiliation to the models

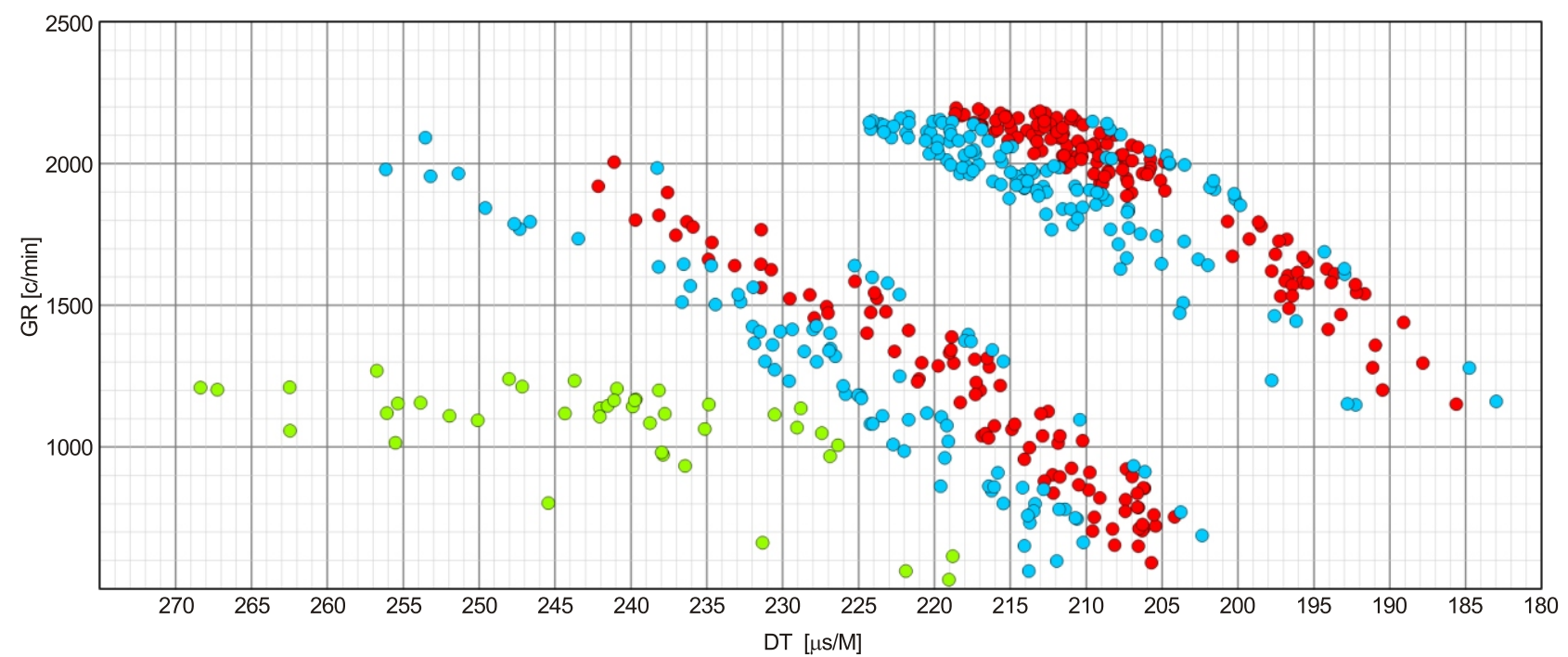

Fig. 11. Natural radioactivity (GR) vs. interval transit time (DT) for the rock models distinguished

Dygowo-1 borehole; Carboniferous and Devonian formations; colours as in Figure 3; black dots - Carboniferous and Devonian borehole log data without affiliation to the models 
zoic clastic rocks which formed the basis for the digital rock model construction (Madonna et al., 2012; Andrä et al., 2013).

Digital rock models concentrated the rock samples with similar reservoir and elastic properties. Samples with better reservoir and elastic properties were extracted from all material analysed. The digital models distinguished formed the basis for the correlation of laboratory and borehole logging results.

The digital model approach applied to the borehole log data also enabled the scaling of laboratory measurements and borehole logging results. Transferring the laboratory information of micro (or nano) scale to the meso scale (results of borehole logs) as well as macro scale (seismics) is an important issue from the point of view of detailed reservoir rock analysis and also for a global approach in sedimentary basin analysis. Scaling of laboratory measurements and borehole logging results was derived by use of models from cluster analysis in investigating intervals equivalent in parameter characterization in the borehole logs profiles.

An interesting result of the digital models is the fact that model 2 (the worst reservoir potential) consists not only of mudstones but also of sandstones. It emerged that these sandstones, different in age, are characterized by very poor petrophysical properties, e.g. low porosity, small pore diameters. The sandstone samples analysed were almost similar regarding their mineral contents, other than sample 137. Total and effective porosity had the lowest values. Probably, these effects are connected with the high levels of compaction and cementation and the tectonic regime. Moreover, model 3 (the best reservoir potential) is represented only by sandstones that are mainly Cambrian and Carboniferous in age. Most of the samples came from the Warsaw and Lublin synclinoria. Total and effective porosity was relatively the highest in these samples. In conclusion, the analysed sandstones from model 3 experienced better conditions of diagenesis and tectonic regime.

Considering Figures 4-6, many points had higher values of parameters obtained from borehole logs than in the laboratory. The discrepancy is connected with the specificity of the measurements. Laboratory measurements are usually conducted on core samples sampled from cores deposited in the core archives and geological samples, free of natural moisture and the influence of reservoir conditions: pressure (stress relief after taking out the core from the borehole) and temperature. By way of example, compressional velocity can be larger in natural conditions in clastic rocks (sonic logs) in comparison to laboratory measurements of compressional velocity on core samples. Borehole log results represent rocks in the physical fields of their natural habitat (e.g., reservoir pressure and temperature). The white point in Figure 6 represents a sandstone sample. The discrepancy in shaliness values from borehole logging (VSH) and laboratory measurements $(\mathrm{Vcl})$ is related to the methodology of the measurement results compared. The borehole logging interpretation showing high shaliness provides averaged information about the rock from layers of about $30 \mathrm{~cm}$ in thickness, due to the vertical resolution of the gamma ray log (GR). Direct laboratory measurement was made on the small part of core in which a high amount of anhydrite was detected (about $78 \%$ of quartz, $20 \%$ of anhydrite and only $2 \%$ of clay minerals), which is why a considerable difference was observed between the results. Higher values from laboratory measurements were observed for several porosity values. This effect is connected with the sonic log use for porosity calculation, which does not detect secondary porosity, while laboratory measurements provide total porosity.

In some boreholes it was impossible to distinguish intervals with the parameters as set out in the digital models, when the laboratory results differed significantly from the results from bore- hole logs. This was related to the specificity of the methods. Laboratory measurements provided point information obtained directly from the rock sample, while borehole logging obtains average petrophysical parameters due to the vertical resolution of borehole logging devices and the indirect means of obtaining measurements. The discrepancies between the results of laboratory measurements and borehole logging resulted in the lack of intervals assignment to appropriate rock models.

The data from borehole intervals of characteristic parameters corresponding to the digital models built on the basis of laboratory measurements were grouped together in spite of different rock ages in order to find the similarities and differences in petrophysical parameters of rocks. This approach allows finding and limiting the coring intervals which differ in these parameters. Within the groups of data assigned to digital models, detailed correlations between crucial parameters from logs and from laboratory results were established. Analyzing the results obtained from laboratory measurements and borehole logging it appeared that Precambrian and Palaeozoic sedimentary rocks revealed reservoir potential. High correlations between log parameters were established within the log intervals corresponding to parameter characterization from 3 models from laboratory measurements. This showed that implementation of laboratory results clustering to log intervals allows the grouping of petrophysical parameters of Precambrian and Palaeozoic rocks, obtained by in situ measurements, into high-correlative intervals.

\section{CONCLUSIONS}

Digital models of Precambrian and Paleozoic sedimentary rocks were focused on similarities and differences in their physical properties. A large amount of laboratory data was considered to provide the maximum possible information from the rocks analysed, was compared with archival borehole logging data, limited in number of petrophysical parameters. Nevertheless, these examples showed that it was possible to select sufficient information from the logs, that were compatible with the laboratory results.

Several conclusions can be drawn:

- The digital rock models divided the material analysed with respect to petrophysical parameters, important to exploration and production, into 3 groups (clusters) of parameter characterizations.

- Digital models were the basis for upscaling of the micro and nano scale laboratory results and borehole logging data representing the meso scale. This procedure was connected with cluster analysis which resulted in digital model (groups, clusters) construction. Groups were characterized by different petrophysical values of parameters. Then, the application of digital models was applied to borehole logging intervals, resulting in the selection of log intervals within the digital models from laboratory measurements.

- High correlations were established between the log petrophysical parameters in selected models (digital rock models).

- The best reservoir properties were revealed in clastic rocks classified to the digital model that consisted mainly of Carboniferous and Cambrian sandstones (model 3). The poorest reservoir properties were typical of rocks assigned to sandstone and mudstone samples of different ages (model 2), which indicates that the material is also diverse as regards their original sedimentation environments. 
- The approach devised allows more precise interpretation of archival and modern borehole logging and can be used to decrease coring intervals into intervals with different petrophysical parameters.

- The models ordered the material with respect to the effectiveness of the diagenesis processes which influenced pore space development.

The credibility of the digital models was improved by using very large and diverse laboratory dataset of parameters. The different ages of the rock samples was taken into account in the research but the main role in digital model construction was played by the parameter values and the aim of analyzing low-porosity and low-permeability, tight rocks.

These techniques of laboratory and borehole logging data processing and the resultant digital models of rock characterization may be regarded as an example of specialist interpretation of archival data. This approach allows the applyication of high-correlative relations between log parameters of different intervals and boreholes.
Acknowledgements. The author is particularly grateful to the reviewers, M. Dohnalik, A. Poszytek and E. Szynkaruk, whose observations improved the article, and is grateful to the Polish Ministry of the Environment and Polish Geological Institute - National Research Institute, Warsaw, Poland for the data. Laboratory measurements apart from mercury porosimetry and compressional tests were made at the Oil and Gas Institute National Research Institute, Kraków, Poland. Mercury porosimetry measurements were made in AGH UST, Faculty of Geology, Geophysics and Environment Protection, Department of Fossil Fuels by Dr. R. Semyrka. Uniaxial compression tests were carried out in AGH UST, Faculty of Mining and Geoengineering, thanks to Dr. D. Flisiak. The project was funded by the National Science Centre on the basis of decision DEC-2011/03/N/ST10/05354. no. AGH 18.18.140.244. The author is grateful to Schlumberger Information Solutions for making possible the use of Techlog software, which has been supplied under a Donation Agreement between AGH UST and Schlumberger.

\section{REFERENCES}

Andrä, H., Combaret, N., Dvorkin, J., Glatt, E., Han, J., Krzikalla, F., Lee, M., Madonna, C., Marsh, M., Mukerji, T., Ricker, S., Saenger, E.H., Sain, R., Saxena, N., Wiegmann, A., Zhan, X., 2013. Digital rock physics benchmarks - Part II: Computing effective properties. Computers \& Geosciences, 50: 33-43.

Bakun-Czubarow, N., 1984. Petrology and elements of geochemistry. Constitution of the Earth's Interior. In: Physics and Evolution of the Earth's Interior (eds. J. Leliwa-Kopystyński and R. Teisseyre): 326-358. Elsevier, Amsterdam-Oxford-New York, Polish Scientific Publishers, Warszawa.

Bielecki, J., Bożek, S., Lekki, J., Stachura, Z., Kwiatek, W.M., 2009. Applications of the Cracow X-ray microprobe in tomography. Acta Physica Polonica A, 115: 537-541.

Botor, D., Papiernik, B., Maćkowski, T., Teicher, B., Kosakowski, P., Machowski, G., Górecki, W., 2013. Gas generation in Carboniferous source rocks of the Variscan foreland basin: implications for a charge history of Rotliegend deposits with natural gases. Annales Societatis Geologorum Poloniae, 83: 353-383.

Brace, W.F., 1966. Dilatancy in the fracture of crystalline rock. Journal of Geophysical Research, 71: 3939-3953.

Coates, G.R., Xiao, L., Prammer, M.G., 1999. NMR Logging Principles \& Applications. Halliburton Energy Services, Houston.

Dohnalik, M., 2013. Improving the ability of determining reservoir rocks parameters using $X$-ray computed microtomography. Unpublished Ph.D. thesis, AGH University of Science and Technology, Kraków.

Dudek, L., Stadtmuller, M., 2010. Application of 3D modeling using PetroCharge simulation to determine quantitative resources of crude oil and natural gas by utilisation of geophysical well logging profiles (in Polish with English summary). Nafta-Gaz, 66 : 973-986.

Dvorkin, J., Armbruster, M., Baldwin, Ch., Fang, Q., Derzhi, N., Gomez, C., Nur, B., Nur, A., Mu, Y., 2008. The future of rock physics: computational methods vs. lab testing. First Break, 26 : 63-68.

Hartigan, J.A., Wong, M.A., 1978. Algorithm 136. A k-means clustering algorithm. Applied Statistics, 28: 100.

Jarzyna, J., Bała, M., Krakowska, P., 2013. Multi-method approach to velocity determination from acoustic well logging. Annales Societatis Geologorum Poloniae, 83: 133-147.
Jarzyna, J., Krakowska, P., Puskarczyk, E., Semyrka, R., 2015. Rock reservoir properties from the comprehensive interpretation of nuclear magnetic resonance and mercury injection porosimetry laboratory results. Applied Magnetic Resonance, 46: 95-115.

Kiersnowski, H., Buniak, A., Kuberska, M., SrokowskaOkońska, A., 2010. Tight gas accumulations in Rotliegend sandstones of Poland (in Polish with English summary). Przegląd Geologiczny, 58: 335-346.

Klinkenberg, L.J., 1941. The permeability of porous media to liquids and gases. Drilling and Production Practice, American Petroleum Institute: $200-213$.

Kotarba, M.J., 2010. Geology, ecology and petroleum of the lower Paleozoic strata in the Polish part of the Baltic region. Geological Quarterly, 54 (2): 103-108.

Krakowska, P., Puskarczyk, E., 2015. Tight reservoirs properties by Nuclear Magnetic Resonance, Mercury Porosimetry and Computed Microtomography laboratory techniques. Case study of Palaeozoic clastic rocks. Acta Geophysica, 63: 789-814.

Krakowska, P., Jarzyna, J., Wawrzyniak-Guz, K., Puskarczyk, E., Zych, M., 2016. Heterogeneity analysis of the Polish shale gas formations based on results of laboratory measurements. Proceedings of 16 International Multidisciplinary Scientific Geoconference SGEM 2016, 30 June-6 July, Albena, Bulgaria, 3: 817-823.

Madonna, C., Almqvist, B.S.G., Saenger, E.H., 2012. Digital rock physics: numerical prediction of pressure-dependent ultrasonic velocities using micro-CT imaging. Geophysical Journal International, 189: 1475-1482.

Marcinowski, R., 2004a. Słownik jednostek litostratygraficznych Polski (in Polish). Wersja podstawowa (grudzień 2004). Tom I: jednostki formalne prekambru i paleozoiku. Państwowy Instytut Geologiczny - PIB, Warszawa.

Marcinowski, R., 2004b. Słownik jednostek litostratygraficznych Polski (in Polish). Wersja podstawowa (grudzień 2004). Tom II: jednostki nieformalne prekambru i paleozoiku. Państwowy Instytut Geologiczny, Warszawa.

Modliński, Z., Szymański, B., Teller, L., 2006. The Silurian lithostratigraphy of the Polish part of the Peri-Baltic Depression 
(N Poland) (in Polish with English summary). Przegląd Geologiczny, 54: 787-796.

Pittman, E., 1992. Relationship of porosity and permeability to various parameters derived from mercury injection - capillary pressure curves for sandstones. AAPG Bulletin, 76: 191-198.

Poprawa, P., 2010. Shale gas potential of the Lower Palaeozoic complex in the Baltic and Lublin-Podlasie basins (Poland) (in Polish with English summary). Przegląd Geologiczny, 58: 226-249.

Poprawa, P., Kiersnowski, H., 2008. Potential for shale gas and tight gas exploration in Poland (in Polish with English summary) Biuletyn Państwowego Instytutu Geologicznego, 429: 145-152.

Porębki, S.J., Prugar, W., Zacharski, J., 2013. Silurian shales of the East European Platform in Poland - some exploration problems. Przegląd Geologiczny, 61: 630-638.

Puskarczyk, E., Jarzyna, J., Porębski, S., 2015. Application of multivariate statistical methods for characterizing heterolithic reservoirs based on wireline log - example from the Carpathian Foredeep Basin (Middle Miocene, SE Poland). Geological Quarterly, 59 (1): 157-168.

Semyrka, R., Jarzyna, J., Semyrka, G., Kaźmierczuk, M., Pikulski, L., 2010. Reservoir parameters of lithostratigraphic successions of the lower Paleozoic strata in the Polish part of the Baltic region based on laboratory studies and well logs. Geological Quarterly, 54 (2): 227-240.

Stock, S.R., 2009. MicroComputed Tomography. Methodology and Application. CRS Press, Taylor and Francis Group, Boca Raton.
Straley, Ch., Rossini, D., Vinegar, H., Tutunjian, P., Morris, Ch., 1997. Core analysis by low field NMR. The Log Analyst, 38: 84-94.

Such, P., Leśniak, G., Słota, M., 2010. Quantitative porosity and permeability characterization of potential Rotliegend tight gas reservoirs (in Polish with English summary). Przegląd Geologiczny, 58: 345-351.

Swanson, B.F., 1981. A simple correlation between permeabilities and mercury capillary pressures. Journal of Petroleum Technology, 8234: 2488-2504.

StatSoft Inc., 2011. STATISTICA (data analysis software system), version 10, www.statsoft.com

Szabó, N.P., 2011. Shale volume estimation based on the factor analysis of well logging data. Acta Geophysica, 59: 935-953.

Tryon, R.C., 1939. Cluster Analysis. McGraw-Hill, New York.

Wójcicki, A., Kiersnowski, H., Dyrka, I., Adamczak-Biały, T., Becker, A., Głuszyński, A., Janas, M., Kozłowska, A., Krzemiński, I., Kuberska, M., Pacześna, J., Podhalańska, T., Roman, M., Skowroński, L., Waksmudzka, M.I., 2014. Prognostyczne zasoby gazu ziemnego w wybranych zwięzłych skałach zbiornikowych Polski (in Polish). Państwowy Instytut Geologiczny, Warszawa.

Żelaźniewicz, A., Aleksandrowski, P., Buła, Z., Karnkowski, P.H., Konon, A., Oszczypko, N., Ślączka A., Żaba J., Żytko K., 2011. Regionalizacja Tektoniczna Polski (in Polish). Committee of Geological Sciences of the Polish Academy of Sciences, KiD Publisher, Wrocław, Poland. 